\title{
Autologous platelet rich plasma - an adjunct to early tangential excision and grafting in burns
}

\author{
Abhinav Aggarwal', Ravi Kumar Chittoria ${ }^{1}$, Souradeep Dutta ${ }^{2}$, Konda Sireesha Reddy ${ }^{1}$, Vinayak Chavan ${ }^{1}$, \\ Saurabh Gupta ${ }^{1}$, Chirra Likhitha Reddy ${ }^{1}$
}

'Department of Plastic Surgery, JIPMER, Puducherry 605006, India.

${ }^{2}$ Department of General Surgery, JIPMER, Puducherry 605006, India.

Correspondence to: Dr. Ravi Kumar Chittoria, Department of Plastic Surgery, JIPMER, Puducherry 605006, India.

E-mail:drchittoria@yahoo.com

How to cite this article: Aggarwal A, Chittoria RK, Dutta S, Reddy KS, Chavan V, Gupta S, Reddy CL. Autologous platelet rich plasma - an adjunct to early tangential excision and grafting in burns. Plast Aesthet Res 2018;5:47. http://dx.doi.org/10.20517/2347-9264.2018.65

Received: 13 Sep 2018 First Decision: 2 Dec 2018 Revised: 3 Dec 2018 Accepted: 3 Dec 2018 Published: 26 Dec 2018

Science Editor: Raúl González-García Copy Editor: Cui Yu Production Editor: Huan-Liang Wu

\begin{abstract}
Aim: To affirm that autologous platelet rich plasma is a useful adjunct to early tangential excision and skin grafting to enhance wound epithelization rates and improve scar quality.

Methods: The study was conducted in JIPMER Tertiary Burn Care Centerfrom November 2017 to February 2018. The study was purely descriptive in nature and no statistical analysis was performed. A total of 12 patients were included with burn wounds involving $10 \%$ to $25 \%$ total body surface area.
\end{abstract}

Results: There was 100\% epithelization noted at the end of 2 weeks for all the 12 participants. Skin graft take was faster with mean $85.4 \%$ take for all the 12 patients within 5 days.

Conclusion: Since it is an autologous component, platelet rich plasma is extremely safe and free of antigenic components. It is relatively simple to prepare, less time taking, cost effective and highly efficacious in improving wound healing and improving the efficacy of the traditional techniques like tangential excision and skin grafting in burn patients.

Keywords: Autologous platelet rich plasma, burns, tangential excision, split skin grafting

\section{INTRODUCTION}

Every year in India total 6-7 million people are afflicted with burns ${ }^{[1]}$. Delayed wound healing, sepsis, and 
secondary complications are routine sequelae of burns. Management of deep dermal burns or full thickness burns has been well described in the literature.

Burn wounds are commonly classified as first degree, second degree and third-degree burns, based on the depth of burn injury. Second degree is further classified into second degree superficial and second degree deep. Second degree deep and third-degree burns are generally benefitted by surgical excision, including tangential excision, while second-degree superficial burns are treated conventionally by dressings and intensive care.

The term "tangential excision" implies excision of superficial necrotic tissue by taking repeated slices parallel to the skin surface using a skin graft knife. The role of early tangential excision in deep dermal burns was given as early as 1968 by Janzekovic ${ }^{[2]}$. Hunt et al.$^{[3]}$ in 1972 published a series of 50 cases being treated by the same technique. Gradually the technique became popular and has now become the standard of care for burn wound management.

In the last century, there has been a lot of research and understanding in the pathophysiology of burn healing, which has led to multitudes of technological innovations in the types of dressings and the approaches to treatment. But in under-resourced health systems like ours, having a huge load of burn patients, there may be limited availability and their cost may be prohibitive for the newer technological innovations and dressings, stimulating the search of cheaper, yet effective adjuncts to the treatment of burn wounds.

One of such innovations is the addition of autologous platelet rich plasma (APRP) to the standard tangential excision and grafting technique.

APRP has been shown to aid wound healing in various aspects of science ${ }^{[4]}$. Platelets have been shown to express around 30 growth factors which besides being chemotactic, also induce proliferation of various cells like fibroblasts, endothelial cells and other precursor cells, which regulate the wound healing ${ }^{[5]}$.

The main growth factors released are platelet derived growth factor (PDGF), transforming growth factor beta 1 (TGF $\beta-1)$, platelet activating factor and epidermal growth factor $(\mathrm{EGF})^{[6]}$.

Moreover, platelets help in hemostasis by forming a platelet plug and express proteases, which help in rapid degradation of the extra cellular matric and basement membrane.

Skin grafting in burns is a challenge for the surgeon due to a depleted physical condition of the patient, deranged biochemical parameters and systemic sepsis. Also, the rates of graft infection are much higher.

Due to the above factors and ease of preparation, APRP can be used as an adjunct to operative procedure and also as a very handy office procedure to boost the healing.

This study is an attempt to throw light on the role of APRP in wound bed preparation and injection of APRP to the wound bed post tangential excision to boost graft take.

\section{METHODS}

The study was conducted in JIPMER Tertiary Burn Care Center, Pondicherry, India from November 2017 to February 2018.

The study was purely descriptive in nature and no statistical analysis was performed.

A total of 12 patients were included with burn wounds involving 10\% to $25 \%$ total body surface area (TBSA). The age of the patients varied from 22 to 46 years. 


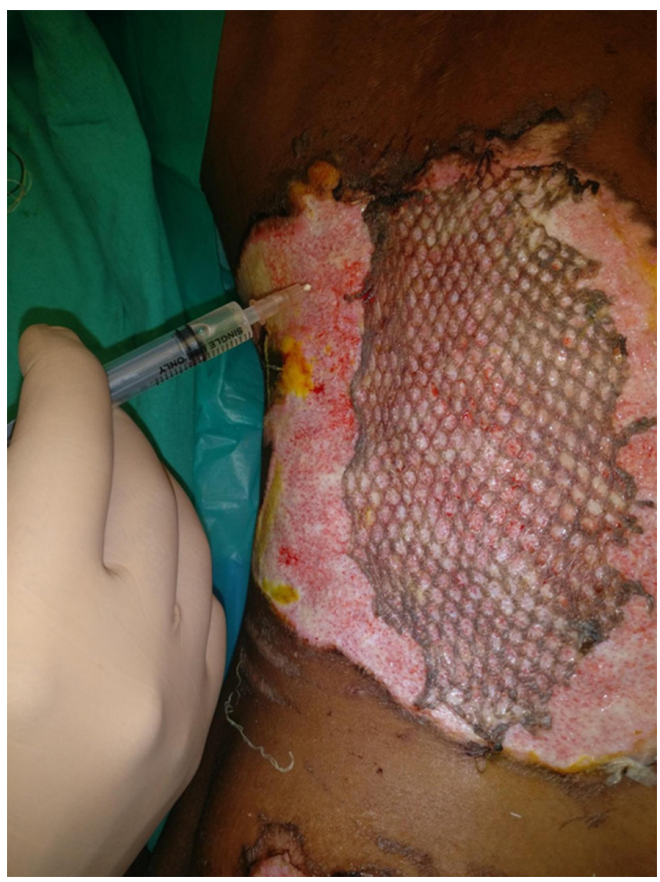

Figure 1. Autologous platelet rich plasma being injected immediately following grafting in patient 4 (Patient S. No. 4)

Tangential excision and autologous split skin grafting was performed for deep dermal burns on day 3 following burns. The cause of the deep burn was thermal in all the cases.

The skin grafts were harvested using a Humby's knife by an experienced surgeon.

Patients with comorbid conditions like diabetes, collagen vascular diseases or any other disease which limits wound healing were excluded. Patients under mechanical ventilation were not taken up for surgery, and hence excluded.

Patients were informed about the study and included after providing signed informed consent.

APRP preparation was done in the operation theatre while debridement/dressing change of the patient using standard and validated technique was described.

Four point five $\mathrm{mL}$ of whole blood was taken from a vein in the periphery and $0.5 \mathrm{~mL}$ of $3.2 \%$ sodium citrate was added to it (blood: anticoagulant at 9:1). The centrifugation tube was placed in centrifugation apparatus. The solution was then subjected to centrifugation at $3000 \mathrm{rpm}$ for $10 \mathrm{~min}$. Three portions were seen in the tube post centrifugation: upper portion containing plasma and platelets, middle portion containing white blood cells with some platelets (buffy coat) and lower portion containing red blood cells. Out of these, middle and lower portions are discarded, the upper portion was transferred and taken in a new tube for re-centrifugation at $4000 \mathrm{rpm}$ for $10 \mathrm{~min}$. Following which two portions were seen: upper 2/3rd portion containing platelet poor plasma and lower $1 / 3$ rd portion which contained platelet rich plasma. Lower $1 / 3$ rd portion was used for APRP therapy.

Multiple subcutaneous injections of 2-3 mL of APRP were given in the selected burn wound following excision of the deep dermal burns using syringe fitted with $26 \mathrm{G}$ needle. APRP injection was done on periphery of the residual raw area, and also on the donor areas of the skin grafts. APRP injection was done on excision and subsequently on every dressing change (day 5, day 7, day 10, day 14 post grafting) [Figure 1]. 


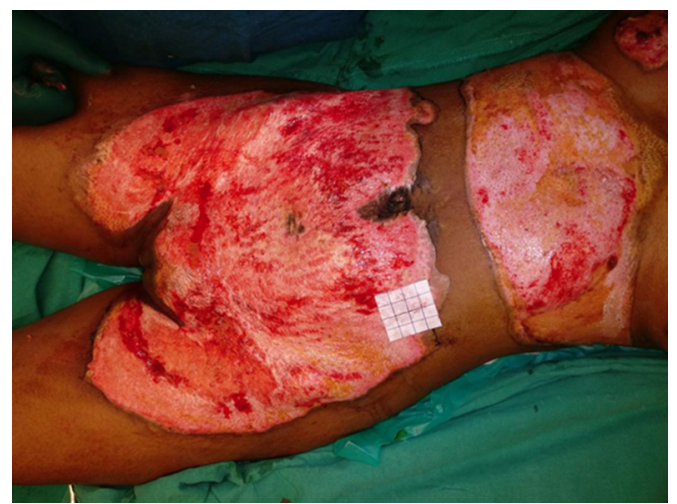

Figure 2. Residual raw area following tangential excision (Patient S. No. 1)

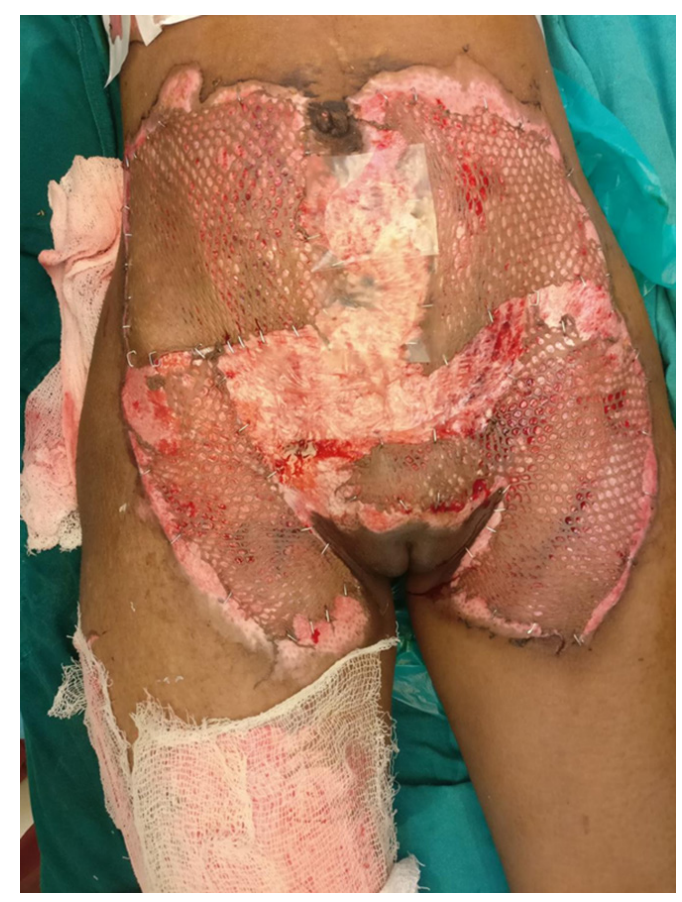

Figure 3. Raw area grafted (day 0) (Patient S. No. 1)

Area epithelized was measured using digital planimetry.

Incidence of wound infection was examined separately.

It must be noted that APRP injection was used for second degree superficial wounds as well in addition to the wound bed for deep burns.

\section{RESULTS}

Twelve patients from our center were included with second degree burn wounds involving $10 \%$ to $25 \%$ TBSA. The age of the patients varied from 22 to 46 years, with a mean age of 32.5 years. Five of them were male, and rest seven, female. The mean graft uptake was $85.4 \%$ at day 5 and $100 \%$ wound epithelization was achieved for all patients by day 14 . The results are tabulated in Table 1. 


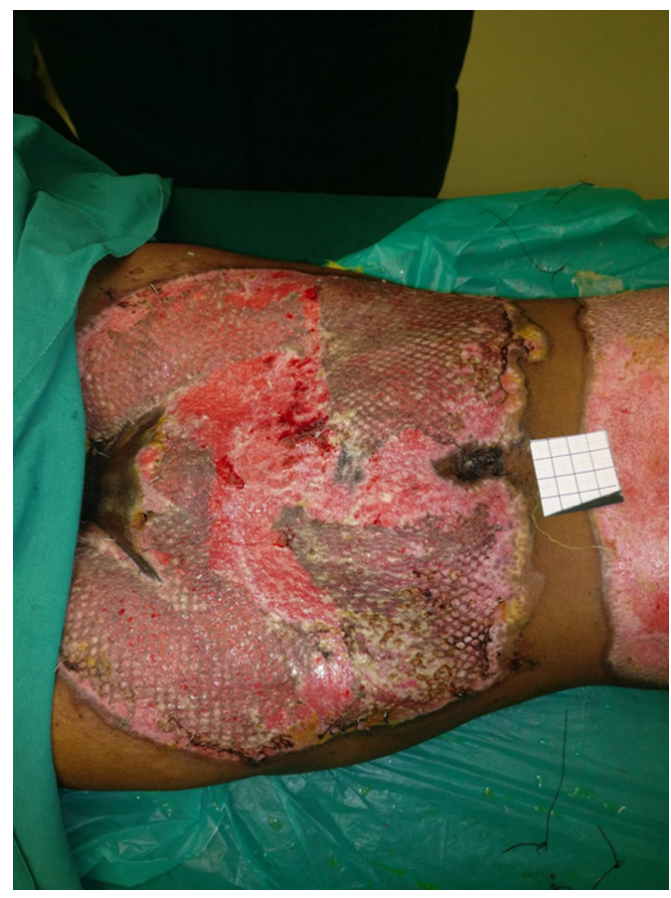

Figure 4. Graft on 1st dressing on day 5 (Patient S. No. 1)

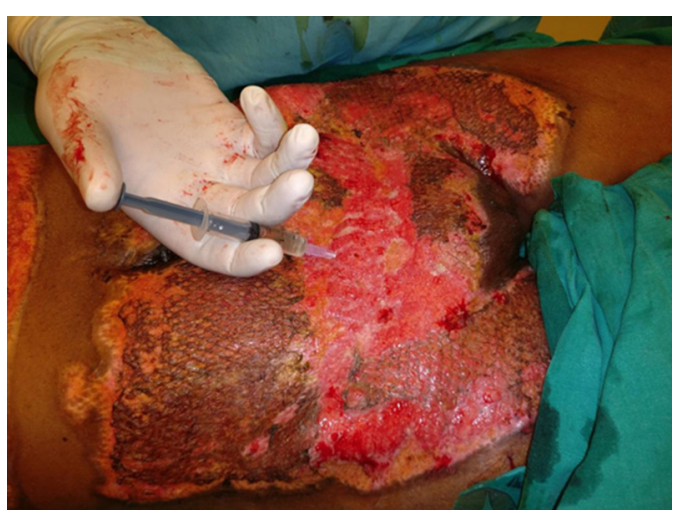

Figure 5. Autologous platelet rich plasma being injected into the residual raw area on day 5 following debridement of dead graft (Patient S. No. 1)

\section{DISCUSSION}

Skin grafts survival occurs via serum imbibition, direct vessel to vessel re-anastomosis (inosculation), and neovascularization. Neovascularization is defined by ingrowth of new vessels from the recipient site into the graft.

APRP as contains a high concentration of alpha granules, is an easy and a very cost-effective approach to obtaining high concentrations of these growth factors. These alpha granules of platelets are known to contain growth factors such as PDGF, vascular endothelial growth factor, TGF, EGF, which promote angiogenesis, cell proliferation, maturation, and matrix formation as described above $e^{[7]}$.

The application of APRP results in prompt tissue regeneration and a reduced risk of infection, pain, and loss of blood. El-Sharkawy et al. ${ }^{[8]}$ in their study have suggested that platelet rich plasma also suppresses cytokine release, thus limiting inflammation, and promoting tissue regeneration. Pallua et al ${ }^{[9]}$ have reported 


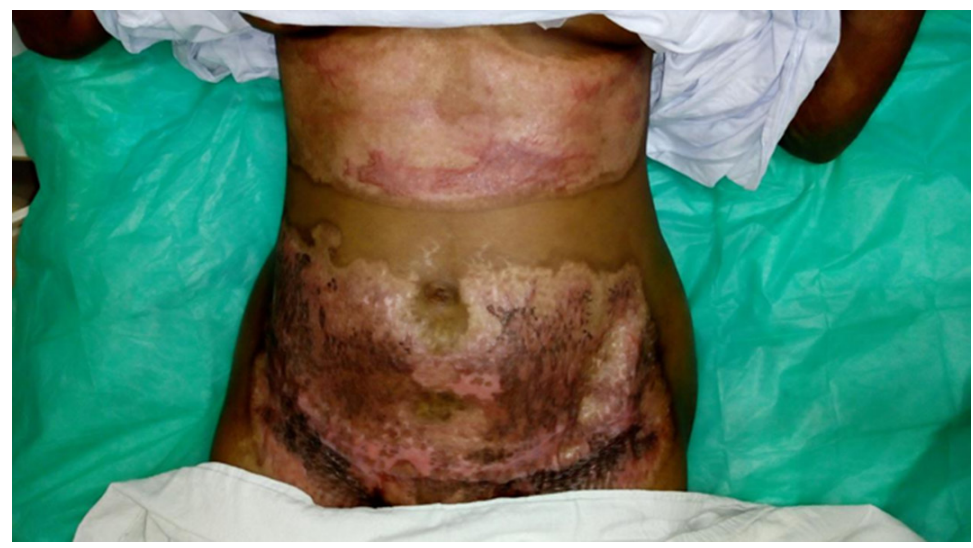

Figure 6. Fully epithelialized wound at day 14 (Patient S. No. 1)

Table 1. Demographic details of the patients and graft uptake on the specified post operative day

\begin{tabular}{|c|c|c|c|c|c|c|c|c|c|c|}
\hline $\begin{array}{l}\text { S. } \\
\text { No. }\end{array}$ & Age & Gender & $\begin{array}{c}\text { TBSA } \\
\text { burn } \\
(\%)\end{array}$ & $\begin{array}{c}\text { Area excised } \\
\text { and grafted (\%) }\end{array}$ & $\begin{array}{c}\text { APRP } \\
\text { used }(\mathrm{mL})\end{array}$ & $\begin{array}{c}\text { Graft take at } \\
\text { day } 5(\%)\end{array}$ & $\begin{array}{c}\text { Wound } \\
\text { epithelized at } \\
\text { day } 7(\%)\end{array}$ & $\begin{array}{c}\text { Graft take } \\
\text { at day } 7 \\
(\%)\end{array}$ & $\begin{array}{c}\text { Wound } \\
\text { epithelized at } \\
\text { day } 10(\%)\end{array}$ & $\begin{array}{c}\text { Wound } \\
\text { epithelized at } \\
\text { day } 14(\%)\end{array}$ \\
\hline 1 & 26 & $\mathrm{~F}$ & $12 \%$ & $6 \%$ & 2 & $75 \%$ & $70 \%$ & $70 \%$ & $90 \%$ & $100 \%$ \\
\hline 2 & 35 & M & $15 \%$ & $15 \%$ & 3 & $90 \%$ & $75 \%$ & $90 \%$ & $95 \%$ & $100 \%$ \\
\hline 3 & 28 & $M$ & $20 \%$ & $15 \%$ & 4 & $100 \%$ & $84 \%$ & $95 \%$ & $95 \%$ & $100 \%$ \\
\hline 4 & 40 & $\mathrm{~F}$ & $16 \%$ & $10 \%$ & 4 & $85 \%$ & $74 \%$ & $80 \%$ & $90 \%$ & $100 \%$ \\
\hline 5 & 29 & $M$ & $20 \%$ & $10 \%$ & 3 & $95 \%$ & $85 \%$ & $90 \%$ & $100 \%$ & $100 \%$ \\
\hline 6 & 22 & M & $18 \%$ & $15 \%$ & 3 & $70 \%$ & $65 \%$ & $70 \%$ & $85 \%$ & $100 \%$ \\
\hline 7 & 46 & $\mathrm{~F}$ & $20 \%$ & $8 \%$ & 2 & $80 \%$ & $55 \%$ & $75 \%$ & $80 \%$ & $100 \%$ \\
\hline 8 & 42 & $\mathrm{~F}$ & $16 \%$ & $7 \%$ & 3 & $90 \%$ & $65 \%$ & $85 \%$ & $75 \%$ & $100 \%$ \\
\hline 9 & 38 & $\mathrm{~F}$ & $18 \%$ & $12 \%$ & 2 & $85 \%$ & $70 \%$ & $80 \%$ & $90 \%$ & $100 \%$ \\
\hline 10 & 26 & M & $12 \%$ & $5 \%$ & 4 & $95 \%$ & $70 \%$ & $75 \%$ & $100 \%$ & $100 \%$ \\
\hline 11 & 22 & $\mathrm{~F}$ & $17 \%$ & $6 \%$ & 3 & $85 \%$ & $60 \%$ & $85 \%$ & $70 \%$ & $100 \%$ \\
\hline 12 & 36 & $\mathrm{~F}$ & $15 \%$ & $4 \%$ & 2 & $75 \%$ & $55 \%$ & $90 \%$ & $85 \%$ & $100 \%$ \\
\hline
\end{tabular}

TBSA: total body surface area; APRP: autologous platelet rich plasma; F: female; M: male

that application of platelet-rich plasma for burn patients accelerates re-epithelization. In another study by Choi et al. ${ }^{[10]}$, the subcutaneous injection of platelet rich plasma in a rabbit skin flap was shown to promote vasculogenesis and increase flap survival.

The study shows good graft take, no infections, a smooth post operative course and a faster rate of epithelization. These findings can be attributed to the addition of application of APRP to the wound bed. The serial follow up images of a patient (S. No. 1) are shown after tangential excision [Figure 2], placing the split skin graft [Figure 3], graft inspection on day 5 [Figure 4], APRP being injected after debridement of the necrosed graft [Figure 5] and after the wound was fully healed [Figure 6].

It should be noted, it is prudent to take APRP as the sole factor responsible for a good post operative outcome following tangential excision and grafting. The importance of time tested burn strategies like nutrition, effective nursing and maintainance of strict asepsis are of paramount importance. APRP is just an adjunct which can be effective in improving the results.

Being a pilot study, this shows a lot of promise and further large multicenter trial is needed to substantiate the same. 


\section{DECLARATIONS}

\section{Authors' contributions}

Study design and conception: Chittoria RK

Data collection and research: Aggarwal A

Data interpretation and review: Dutta S, Reddy S, Chavan V, Gupta S, Reddy L

\section{Availability of data and materials}

All data supporting the article is available with the medical records department of the institute. Can be reproduced as and when needed.

\section{Financial support and sponsorship}

None.

\section{Conflicts of interest}

All authors declared that there are no conflicts of interest.

\section{Ethical approval and consent to participate}

Due informed consent was obtained from all patients before including them into the study including photographic consent. Ethical clearance was obtained from the institute in which the study was done.

\section{Consent for publication}

Full informed consent for publication has been obtained from the individuals included in the study.

\section{Copyright}

(c) The Author(s) 2018.

\section{REFERENCES}

1. Gupta JL, Makhija LK, Bajaj SP. National programme for prevention of burn injuries. Indian J Plast Surg 2010;43:S6-10.

2. Janzekovic Z. The burn wound from the surgical point of view. J Trauma1975;15:42-62.

3. Hunt JL, Sato R, Baxter CR. Early tangential excision and immediate mesh autografting of deep dermal hand burns. Ann Surg 1979;189:147-51.

4. Everts PA, Knape JT, Weibrich G, Schönberger JP, Hoffmann J, et al. Platelet-rich plasma and platelet gel: a review. J Extra Corpor Technol 2006;38:174-87.

5. Eppley BL, Woodell JE, Higgins J. Platelet quantification and growth factor analysis from platelet-rich plasma: implications for wound healing. Plast Reconstr Surg 2004;114:1502-8.

6. Eppley BL, Pietrzak WS, Blanton M. Platelet-rich plasma: a review of biology and applications in plastic surgery. Plast Reconstr Surg 2006;118:147e-59e.

7. Sánchez-González DJ, Méndez-Bolaina E, Trejo-Bahena NI. Platelet-rich plasma peptides: key for regeneration. Int J Pept 2012;2012:532519.

8. El-Sharkawy H, Kantarci A, Deady J, Hasturk H, Liu H, et al. Platelet-rich plasma: growth factors and pro- and anti-inflammatory properties. J Periodontol 2007;78:661-9.

9. Pallua N, Wolter T, Markowicz M. Platelet-rich plasma in burns. Burns 2010;36:4-8.

10. Choi HN, Han YS, Kim SR, Kim HK, Kim H, et al. The effect of platelet-rich plasma on survival of the composite graft and the proper time of injection in a rabbit ear composite graft model. Arch Plast Surg 2014;41:647-53. 